\title{
ANALISA PENERAPAN SERVER DEPLOYMENT MENGGUNAKAN KUBERNETES UNTUK MENGHINDARI SINGLE OF FAILURE
}

\author{
Lilik Widyawati $^{1 *}$, Heroe Santoso ${ }^{2}$, Hamdika Budiman $^{3}$ \\ ${ }^{1,3}$ Ilmu Komputer, Universitas Bumigora \\ ${ }^{2}$ Rekayasa Perangkat Lunak Aplikasi, Universitas Bumigora \\ email: lilikwidya@universitasbumigora.ac.id*
}

\begin{abstract}
Abstrak: Sistem komputasi terdistribusi menjadi salah satu kebutuhan dalam implementasi aplikasi berbasis server seperti database server dan web server agar tercapainya tingkat performansi tinggi. Masalah yang sering terjadi adalah kegagalan pada server sehingga perfrorma dari sebuah server terganggu, sehingga dibutuhkan suatu teknik deploy dapat digunakan untuk menyediakan sistem terdistribusi dengan performansi tinggi. Virtualisasi berbasis container menjadi pilihan untuk menjalankan sistem terdistribusi karena arsitektur yang ringan, kinerja yang cepat, dan efisiensi sumber daya. Salah satu virtualisasi berbasis container adalah memperkenalkan alat pengembangan sistem terdistribusi yang disebut Kubernetes, yang memungkinkan memanajemen deploy server untuk menyediakan sistem dengan availability yang tinggi. Metodologi pengembangan system yang digunakan adalah Network Development Life Cycle (NDLC). Dari 6 tahapan yang ada, hanya digunakan 3 tahapan yaitu Analysis, Design, dan Simulation Prototyping. Uji coba atau scenario pengujian yang dilakukan adalah Ftp Deploy dan Web Server Nginx sehingga dapat menjaga ketersediaan dan sistem mampu melakukan failover saat terjadi kegagalan pada server.
\end{abstract}

Kata Kunci : Kubernetes, Server Deployment, Server Nginx

Abstract: istributed computing systems are one of the requirements in implementing server-based applications such as database servers and web servers in order to achieve high levels of performance. The problem that often occurs is failure on the server so that the performance of a server is disrupted, so it takes a deployment technique that can be used to provide a distributed system with high performance. Container-based virtualization is the choice for running distributed systems because of its lightweight architecture, fast performance and resource efficiency. One of the container-based virtualisations is the introduction of a distributed systems development tool called Kubernetes, which allows managing server deployments to provide high availability systems. The system development methodology used is the Network Development Life Cycle (NDLC). Of the 6 stages, only 3 stages are used, namely Analysis, Design, and Simulation Prototyping. The test or test scenario carried out is Ftp Deploy and Nginx Web Server so that it can maintain availability and the system is able to failover when a server failure occurs.

Keywords : Kubernetes

\section{PENDAHULUAN}

Sistem komputasi terdistribusi menjadi suatu kebutuhan dalam implementasi aplikasi web berserta software pendukung seperti database server dan web server. Sistem terdistribusi adalah suatu sistem (hardware + software) yang terdiri atas kumpulan dari komputer yang saling terhubung dan terlihat bagi pengguna sistem sebagai suatu sistem komputer tunggal [1]. Beberapa server yang sering digunakan adalah FTP server dan Web server nginx.

FTP (File Transfer Protocol) adalah suatu standar protocol yang digunakan dalam mempertukarkan file antar komputer di dalam jaringan yang mendukung protokol TCP/IP, seperti Internet [2] Untuk memastikan bahwa file terkirim dan diterima tanpa terjadi loss pada file yang dipertukarkan, FTP menggunakan protokol TCP pada lapisan transpot dan Web Server Nginx adalah sistem web server terdistribusi yang terkenal karena stabil dan memiliki tingkat performansi tinggi. Virtualisasi berbasis container menjadi pilihan untuk menjalankan sistem terdistribusi karena arsitektur yang ringan, kinerja yang cepat, dan efisiensi sumber daya [3].

Server tunggal tidak cukup untuk mendukung lalu lintas yang tinggi dan dapat menyebabkan single point of failure (SPOF), yaitu kondisi server yang mengalami kegagalan dalam merespon request client maka sistem akan tidak berfungsi dikarenakan terlalu banyak menangani request dari client [4], yang tidak dapat diakses saat terdapat permasalahan pada server merupakan hal yang dihindari oleh pengguna. Salah satu teknik untuk mengatasi masalah tersebut adalah menerapkan sistem terdistribusi menggunakan teknik deploy. memperkenalkan alat pengembangan sistem terdistribusi yang disebut Kubernetes, Kubernetes merupakan platform open-source yang digunakan untuk melakukan manajemen workloads aplikasi yang dikontainerisasi, serta menyediakan konfigurasi dan otomatisasi secara deklaratif [5] sehingga memungkinkan memanajemen deploy server dan memudahkan dalam proses container pada multihost.

\section{TINJAUAN PUSTAKA}

Terdapat beberapa penelitian yang telah dilakukan oleh peneliti terkait sistem terdistribusi. Dawood dkk, (2014) melakukan penelitian membandingkan tiga sistem terdistribusi yaitu Nginx, Apache, dan Lighttpd. Penelitian tersebut menghasilkan bahwa diantara ketiga aplikasi web 
server tersebut, Nginx memiliki kinerja terbaik dan memiliki tingkat performansi tinggi [6]. Sedangkan penelitian yang dilakukan oleh Kusuma dkk, (2017) menyatakan bahwa teknologi virtualisasi container dapat menjadi solusi untuk menjalankan sistem terdistribusi yang mudah dikonfigurasi dan mempunyai skalabilitas tinggi [7]. Sebaliknya, penelitian yang dilakukan oleh Apridayanti dkk, (2018) menyampaikan bahwa teknik virtualisasi container menggunakan Kubernetes untuk manajemen container [8].

Penelitian terkait kubernetes juga pernah dilakukan oleh yedutun (2019), fokus penelitian yang dilakukan adalah implementasi kubernetes untuk mendukung scalability, hasil implementasi scalability terhadap container adalah adanya penghematan cpu usage pod pada saat scalability diterapkan. Dikarenakan adanya pembagian container yang tersebar ditiap worker nya [9].

\section{METODE}

Metode pengemanagan system yang digunakan adalah NDLC,

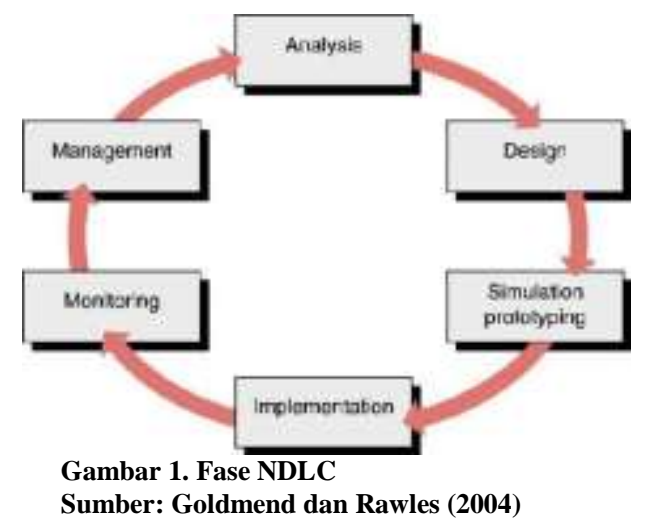

Dari keenam fase yang terdapat pada NDLC, penulis hanya menggunakan 3 (tiga) fase antara lain sebagai berikut: Analysis, design dan simulation Prototyping.

Pada fase Analysis penulis melakukan pengumpulan data dengan cara studi literatur, yaitu penulis membaca artikel ilmiah dan jurnal untuk mendapatkan informasi mengenai Kubernetes, Virtualisasi berbasis Container, Web Service Nginx serta Ftp server, data yang telah terkumpul kemudian dianalisis.

Berdasarkan hasil penelusuran artikel jurnal ilmiah yang terkait, maka dapat diketahui bahwa belum terdapat penelitian tentang sistem web server Nginx dan Ftp Server berbasis fauria menggunakan Kubernetes agar tercapainya sistem terdistribusi untuk menyediakan ketersediaan tinggi serta memberikan toleransi kesalahan. Dari permasalahan dan hasil analisa tersebut maka mendorong penulis untuk melakukan penelitian tentang Analisa Penerapan Web Server Nginx dan Ftp Server fauria
Menggunakan Kubernetes.

Pada tahap Design penulis membuat rancangan yang meliputi rancangan jaringan uji coba, rancangan system menggunakan Kubernetes, pengalamatan IP, serta kebutuhan perangkat keras dan perangkat lunak. Adapun rancangan system dapat dilihat pada gambar dibawah ini.

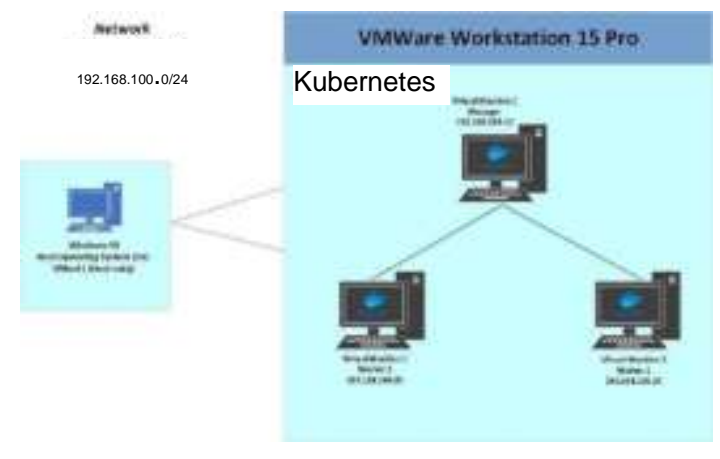

Gambar 2. Rancangan Sistem Kubernetes

Dalam rancangan uji coba akan disimulasikan secara virtualisasi menggunakan VMware Workstation yang dijalankan pada 1 (satu) laptop. Di dalam VMware Workstation terdapat 3 (tiga) virtual machine yang difungsikan sebagai master dengan IP 192.168.100.10, worker 1 dengan IP 192.168.100.20 dan worker 2 dengan IP 192.168.100.30. Sistem operasi yang digunakan adalah Linux CentOS release 7.7.1908 dan di deploy menggunakan Kubernetes. Pada komputer client telah terinstal sistem operasi windows 10 dan aplikasi browser Google Chrome untuk mengakses web server Nginx.

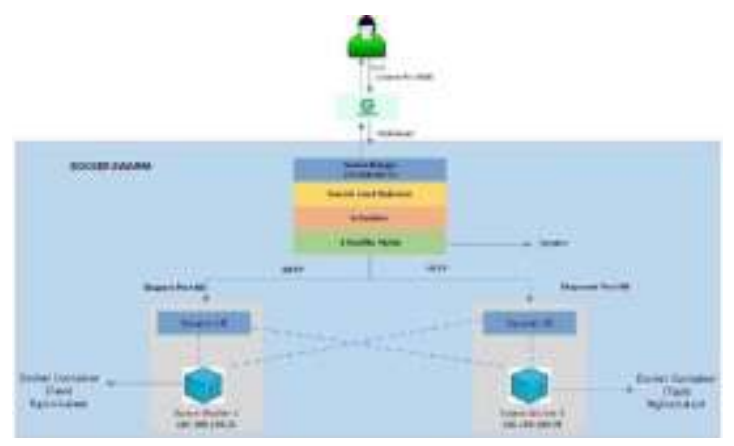

Gambar 3. Rancangan Sistem Web Server Nginx

Sistem dari web server Nginx di deploy menggunakan Kubernetes. Terdapat 3 (tiga) node yaitu master, worker 1 dan worker 2 . Node master bertugas untuk mengatur status deploy, membagikan tugas ke node worker, membuat replika proses, serta memperbaiki kesalahan pada node worker. Pada node master dilakukan pembuatan web server Nginx lalu tersebut direplikasi atau disebarkan pada nodenode worker kemudian pada node master terdapat 
scheduler untuk menjadwalkan atau merutekan pada node dalam deploy sebagai satu atau lebih tugas replika.

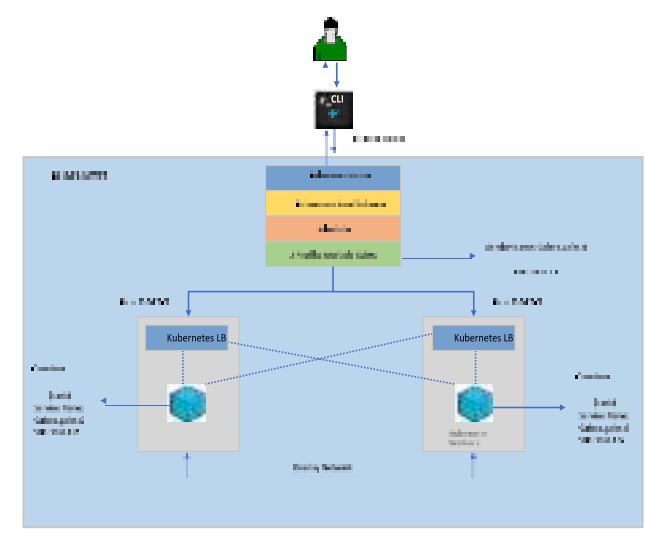

Gambar 4. Rancangan Sistem Ftp Server

Sistem dari Ftp Server di deploy menggunakan Kubernetes. Terdapat 3 (tiga) node yaitu master, worker 1 dan worker 2 . Node master bertugas untuk mengatur status deploy, membagikan tugas ke node worker, membuat replika proses, serta memperbaiki kesalahan pada node worker. Pada node master dilakukan pembuatan Ftp Server lalu tersebut direplikasi atau disebarkan pada node-node worker kemudian pada node master terdapat scheduler untuk menjadwalkan atau merutekan pada node dalam deploy sebagai satu atau lebih tugas replica.

Tahap berikutnya adalah melakukan simulasi dan membuat prototype. Pada fase ini dilakukan instalasi dan konfigurasi serta uji coba system virtualisasi container yang telah di deploy menggunakan Kubernetes.

Uji coba dilakukan dengan mengakses ftp atau web server baik dalam kondisi seluruh server node aktif, dalam kondisi salah satu server node tidak aktif serta dalam kondisi seluruh container down lalu melihat kinerja dari hasil penerapan Kubernetes apakah mampu server atau host yang lainnya untuk menangani request dari client sehingga tercapai fungsi ketersedian (availability).

\section{HASIL DAN PEMBAHASAN}

Instalasi dan konfigurasi dilakukan pada 1 (satu) server yang difungsikan sebagai node master untuk kontroler pada komputer deploy, 2 (dua) server yang difungsikan sebagai node worker untuk mengeksekusi proses yang telah dibagi oleh node master, serta 1 (satu) client yang difungsikan untuk menggunakan yang telah ditentukan.

Pada server yang difungsikan sebagai node master dilakukan instalasi Linux CentOS 7 menggunakan DVD ISO images minimal, konfigurasi pengelamatan IP, instalasi, instalasi Kubernetes sebagai metode server.

Pada server yang difungsikan sebagai node worker dilakukan instalasi Linux CentOS 7 menggunakan DVD ISO images minimal, konfigurasi pengelamatan IP, serta instalasi dan konfigurasi Kubernetes sebagai metode server.

Pada komputer client yang difungsikan untuk menggunakan dilakukan konfigurasi pengelamatan IP agar komputer client dan server dapat terhubung.

Skenario uji coba dilakukan dengan pembuatan web server berbasis Nginx dan Ftp Server Fauria serta dilakukan verifikasi konfigurasi untuk deploy service untuk mengetahui apakah tersebut berhasil tereplikasi pada tiap-tiap node worker.

Uji coba selanjutnya dengan mengakses web server berbasis Nginx dan Ftp Server Fauria serta menganalisa hasil kinerja dari penerapan Kubernetes.

Tabel 1. Pengujian Web server NGINX

\begin{tabular}{|c|c|c|c|}
\hline $\begin{array}{l}\mathrm{N} \\
\mathrm{O}\end{array}$ & Skenario & Hasil & Keterangan \\
\hline 1 & $\begin{array}{l}\text { Akses Web } \\
\text { Server } \\
\text { Nginx } \\
\text { dalam } \\
\text { kondisi } \\
\text { seluruh } \\
\text { server } \\
\text { node aktif }\end{array}$ & $\begin{array}{l}\text { Sistem mampu } \\
\text { melayani } \\
\text { request }\end{array}$ & $\begin{array}{l}\text { Sistem server } \\
\text { menggunakan } \\
\text { Kubernetes } \\
\text { berjalan } \\
\text { dengan baik }\end{array}$ \\
\hline 2 & $\begin{array}{l}\text { Akses Web } \\
\text { Server } \\
\text { Nginx } \\
\text { dalam } \\
\text { kondisi } \\
\text { salah } \\
\text { satu } \\
\text { server } \\
\text { mengalami } \\
\text { kegagalan }\end{array}$ & $\begin{array}{l}\text { Berhasil } \\
\text { diakses } \\
\text { walaupun } \\
\text { salah satu } \\
\text { server node } \\
\text { mengalami } \\
\text { kegagalan }\end{array}$ & $\begin{array}{lr}\text { Container } & \text { pada } \\
\text { server } & \text { node } \\
\text { yang } & \text { down } \\
\text { berpindah } & \text { pada } \\
\text { server } & \text { node } \\
\text { yang } & \\
\text { tersedia/aktif. }\end{array}$ \\
\hline 3 & $\begin{array}{l}\text { Akses Web } \\
\text { Server } \\
\text { Nginx } \\
\text { dalam } \\
\text { keadaan } \\
\text { seluruh } \\
\text { container } \\
\text { down. }\end{array}$ & $\begin{array}{l}\text { berhasil } \\
\text { diakses } \\
\text { walaupun } \\
\text { seluruh } \\
\text { container } \\
\text { down }\end{array}$ & $\begin{array}{l}\text { Sistem } \\
\text { Kubernetes } \\
\text { melakukan Self } \\
\text { Healing dengan } \\
\text { pembuatan } \\
\text { container baru }\end{array}$ \\
\hline
\end{tabular}

Tabel 1 menunjukan bahwa sistem mampu melayani request dari client baik dalam kondisi seluruh server node aktif maupun dalam kondisi salah satu server node tidak aktif termasuk dalam kondisi seluruh container down. Hal tersebut dapat tercapai sebagai dampak dari fungsi dari ketersediaan yang diberikan oleh Kubernetes. Jika salah satu host down maka service akan digantikan dengan host yang sedang aktif.

Ketika salah satu node dalam keadaan down, maka container yang berada pada node tersebut melakukan self-healing dengan membuat container 
baru yang secara otomatis muncul pada salah satu server node yang aktif. Selain itu ketika container pada seluruh server node down, sistem otomatis akan melakukan self-healing dengan pembuatan container baru. Hal tersebut dapat tercapai karena Kubernetes mengimplementasikan Algoritma Konsensus Raft pada node manager untuk mengelola status deploy. Raft adalah protokol untuk mengimplementasikan konsensus terdistribusi yang toleran terhadap kesalahan.

Dengan algoritma Konsensus Raft, node manager dapat memindahkan ke node yang masih aktif sehingga apabila salah satu node mengalami kegagalan, hal ini tidak akan mengganggu sistem yang sedang berjalan sehingga tercapainya ketersediaan dan user tetap mendapatkan balesan dari system.

Tabel 2. Pengujian FTP server Fauria Deploy

\begin{tabular}{|c|c|c|c|}
\hline No & Skenario & Hasil & keterangan \\
\hline \multirow[t]{4}{*}{1} & Membuat & Node yang & Sinkronisasi \\
\hline & $\begin{array}{l}\text { terkoneksi } \\
\text { menggunakan } \\
\text { aplikasi }\end{array}$ & $\begin{array}{l}\text { telah dibuat } \\
\text { berhasil di } \\
\text { sinkronisasi }\end{array}$ & $\begin{array}{ll}\text { Ftp } & \text { server } \\
\text { berhasil } & \end{array}$ \\
\hline & FileZilla & ke seluruh & \\
\hline & Client & $\begin{array}{l}\text { node pada } \\
\text { deploy }\end{array}$ & \\
\hline 2 & $\begin{array}{l}\text { Mengirimkan } \\
\text { file .txt ke } \\
\text { setiap node } \\
\text { kubernetes }\end{array}$ & $\begin{array}{l}\text { File .txt yang } \\
\text { dikimkan } \\
\text { berhasil } \\
\text { sampai ke } \\
\text { node master, } \\
\text { worker 1 dan } \\
\text { worker } 2 \\
\end{array}$ & $\begin{array}{l}\text { Sinkronisasi } \\
\text { File .txt } \\
\text { berhasil. }\end{array}$ \\
\hline \multirow[t]{2}{*}{3} & Mengirimkan & File .pdf yang & Sinkronisasi \\
\hline & $\begin{array}{l}\text { file pdf ke } \\
\text { setiap node } \\
\text { kubernetes }\end{array}$ & $\begin{array}{l}\text { dikimkan } \\
\text { berhasil } \\
\text { sampai ke } \\
\text { node master, } \\
\text { worker } 1 \text { dan } \\
\text { worker } 2\end{array}$ & $\begin{array}{ll}\text { file } & \text {.pdf } \\
\text { berhasil. } & \end{array}$ \\
\hline
\end{tabular}

Tabel 2 menunjukan bahwa sistem mampu melakukan terhadap ftp server yang sudah di deploy pada node master dan di sebarkan ke node worker 1 dan node worker 2. Pada uji coba Ftp server Fauria akan ditampilkan analisa hasil ujicoba meliputi terkoneksi dengan FileZilla client, mengirim file .txt dan file .pdf yang dijalankan pada deploy server menggunakan Kubernetes baik ketika kondisi seluruh server node aktif, kondisi salah satu server node tidak aktif, maupun saat seluruh container pada server node tidak aktif.

Jika salah satu host down maka pada host tersebut akan digantikan atau dipindahkan ke host yang sedang aktif. Tugas pemindahan tersebut di handle oleh node master karena salah satu fungsi dari node manager adalah memperbaiki kesalahan pada node worker. Dengan algoritma Konsensus Raft, node manager dapat memindahkan ke node yang masih aktif sehingga apabila salah satu node mengalami kegagalan, hal ini tidak akan mengganggu sistem yang sedang berjalan sehingga tercapainya ketersediaan dan user tetap mendapatkan balesan dari system.

\section{KESIMPULAN DAN SARAN}

Berdasarkan hasil instalasi, konfigurasi dan ujicoba serta analisa terhadap hasil ujicoba maka dapat diperoleh kesimpulan sebagai berikut:

Kubernetes dapat digunakan untuk melakukan container pada web berbasis Nginx dan Ftp server sehingga dapat terjaga ketersediaannya berdasarkan skenario uji coba mengaktifkan seluruh node, menonaktifkan salah satu node dan menonaktifkan seluruh node pembentuk deploy.

Teknik deploy menggunakan kubernetes dapat menghindari single point of failure dan ketika salah satu atau seluruh node pembentuk deploy mengalami gangguan (tidak aktif) maka sistem secara otomatis akan melakukan self healing untuk membentuk container baru.

Mekanisme failover yang terdapat pada kubernetes berjalan dengan baik, sehingga sistem memiliki ketersediaan tingkat tinggi (high availability Saran memuat berbagai usulan atau pendapat yang sebaiknya dikaitkan oleh penelitian sejenis. Saran dibuat berdasarkan kelemahan, pengalaman, kesulitan, kesalahan, temuan baru yang belum diteliti dan berbagai kemungkinan arah penelitian selanjutnya.

\section{DAFTAR PUSTAKA}

[1] A. Bima, M. Wijawa, J. Soeprapto and Y. Tegar, "Analisa Perancangan Arsitektur Sistem terdistribusi menggunakan metode Nested Transaction pada Lingkungan Kerja Perkantotan Difficulty or Complexityof Bussiness Integration," vol. 7, no. 2, pp. 2-9, 2015.

[2] Yuhefizar, "File Transfer Protokol," in $10 \mathrm{Jam}$ Meng. Internet,teknologi \& Apl, Jakarta, PT Elex media Komputindo, 2008.

[3] A. Terry, "Take Control of Kubernetes," Nginx, $952019 . \quad$ [Online]. Available: https://www.nginx.com/products/nginx-servicemesh. [Accessed 212 2020].

[4] R. Julianto, W. Yahya and S. R. Akbar, "Implementasi Load Balancing Di Web Server Menggunakan Metode Berbasis Sumber Daya CPU Pada Software Defined Networking," JPTIIK, 2017.

[5] Editor, "Apa itu Kubernetes," Kubernetes.io, 9 $102020 . \quad$ [Online]. Available: https://kubernetes.io/id/docs/concepts/overview/ what-is-kubernetes/. [Accessed 212 2020].

[6] R. Dawood, S. F. Qiana and S. Muchallil, "Kelayakan Raspberry Pi Sebagai Web Server: Perbandingan Kinerja Nginx, Apache, Dan Lighttpd Pada Platform Raspberry Pi," Jurnal 
Rekayasa Elektrika, vol. 11, no. 1, pp. 30-35, 2014.

[7] T. P. Kusuma, R. Munadi and D. D. Sanjoyo, "Implementasi Dan Analisis Computer System Dengan Menggunakan Virtualisasi," in $e$ proceeding of engineering, 2017.

[8] S. Apridayanti, "Desain Dan Implementasi Virtualisasi Berbasis Container," Semantik, vol. 4, no. 2, pp. 37-46, 2018.

[9] K. Yedutun, A. Noertjahyana and H. N. Palit, Jurnal Infra, vol. 7, no. 2, 2019. 